\title{
A LIBERALIZAÇÃO COMERCIAL BRASILEIRA VISTA NO ÂMBITO DO MERCOSUL A PARTIR DOS PRODUTOS MANUFATURADOS (2000 A 2010)
}

\author{
THE BRAZILIAN TRADE LIBERALIZATION WITHIN \\ MERCOSUR VIEW FROM MANUFACTURED PRODUCTS \\ (2000-2010)
}

Fagner Mendonça Avelar

Universidade Estadual do Oeste do Paraná/Campus de Toledo - Toledo - PR Brasil

Cristiano Stamm

Universidade Estadual do Oeste do Paraná/Campus de Toledo - Toledo - PR Brasil

Carlos Alberto Gonçalves Junior

Universidade Estadual do Oeste do Paraná/Campus de Toledo - Toledo - PR Brasil

Resumo: O objetivo deste artigo foi analisar o desempenho da economia brasileira em relação ao comércio de produtos manufaturados, destinados aos demais paísesmembros do Mercado Comum do Sul - MERCOSUL no período de 2000 a 2010 . A análise se deu por meio de uma ferramenta analítica que aponta a tendência do setor externo, em qualquer país ou região, chamada de "Índice de Desenvolvimento do Setor Externo - SXi". Além desse, também foram calculados os índices de abertura comercial para produtos manufaturados exportados pelo Brasil. De acordo com os resultados da pesquisa, percebe-se uma relativa melhoria nas relações comerciais brasileiras com os demais países-membros do bloco na medida em que a composição da pauta de exportações, do período analisado, caracterizou-se, em média, por mais de $90 \%$ de produtos com alto valor agregado.

Palavras-Chave: Abertura comercial brasileira. Mercosul. Comércio internacional.

Abstract: The aim of this study was to analyze the performance of the Brazilian economy in relation to trade in manufactured goods destined for other member countries of the Southern Common Market -. MERCOSUR in the period from 2000 to

Redes (St. Cruz Sul, Online), v. 20, nº 3 - Suplemento, p. 401 - 425, set./dez. 2015401 
2010. The analysis was done by means of an analytical tool to study the trend of the external sector in any country or region, which is called "Development Index of the external Sector (SXi)". Besides this, we also calculated the rates of trade liberalization for manufactured products exported by Brazil. According to the survey results, it is noticed that there was a relative improvement in Brazilian trade relations with other member countries of the bloc to the extent that the composition of exports, the analysis period was characterized on average by more $90 \%$ of products with high added value.

Keywords: Brazilian Trade Liberalization. Mercosul. International trade.

\section{INTRODUÇÃO}

O MERCOSUL, bloco integracionista do qual o Brasil participa de forma crescente, tem se tornado um de seus importantes parceiros comerciais, além de ser relevante também considerar o aprofundamento da integração e das interações regionais proporcionadas pelo bloco. $O$ Brasil continua sendo o país com maior peso no bloco, com cerca de 70\% do seu Produto Interno Bruto - PIB. Tem-se que parte considerável das transações comerciais brasileiras com o exterior está ligada ao MERCOSUL, cerca de $20 \%$ das exportações e $17 \%$ das importações totais (MOREIRA e MILHOMENN, 2010).

O Tratado de Assunção, formalizado em março de 1991, veio a definir apenas objetivos gerais do MERCOSUL, bem como os mecanismos para alcançar a integração. Nesse sentido, tratados e protocolos posteriores teriam o objetivo de definir a estrutura do acordo, suas regras de funcionamento e tomada de decisão. Mais de 20 anos depois de sua criação, é fato que o Bloco ainda não realizou plenamente seu processo de integração, constituindo-se, ainda, como uma União Aduaneira Imperfeita (ALMEIDA, 2011). Isso porque ainda conta com uma tarifa externa comum enfraquecida por uma grande quantidade de exceções e um comércio entre países cheio de medidas protecionistas temporárias.

De acordo com Baumann (2011), como em qualquer processo, existem custos e benefícios envolvidos. Segundo esse autor, a decisão de conceder tratamento privilegiado nas trocas com determinado país ou grupo de países, pressupõe uma expectativa de ganhos de médio e longo prazo, sendo assim, acordos comerciais que promovam a criação de "espaços econômicos comuns" entre países podem ser vistos como 
ferramentas para a promoção do desenvolvimento econômico. $\mathrm{Na}$ medida em que haja, entre dois países, semelhança na "preferência social" pelo crescimento do setor manufatureiro, ambos podem beneficiar-se com a redução das barreiras no comércio bilateral. E isso será tanto mais verdadeiro quanto mais baixo o grau de competitividade desses países no mercado internacional de produtos manufaturados.

Johnson (1965) destaca que uma redução discriminatória de barreira comercial permite a um dado país proporcionar ao seu sócio aumento de exportações e produção industrial sem que sua própria produção seja negativamente afetada, por meio de desvio de comércio.

Devido à crescente relevância do setor externo nas economias nacionais, verifica-se que Brasil tem alcançado lugar de destaque entre os países-membros do MERCOSUL. O Brasil, além de ser o maior país do bloco, é formado por uma economia bastante diversificada e tende a possuir um importante papel na integração regional. Dentre a pauta de exportações brasileiras, segundo dados do Ministério do Desenvolvimento, Indústria e Comércio Exterior - MDIC (2013), verificase que esta é composta por mais de $90 \%$ de produtos com maior valor agregado, os chamados produtos manufaturados, segundo a classificação do referido ministério. Como será verificado no desenvolver deste artigo o crescimento expressivo da exportação brasileira desses produtos acarreta grandes melhorias nos setores envolvidos.

Dessa maneira, o presente artigo teve como foco os produtos mais relevantes na pauta de exportações brasileiras com destino aos países do MERCOSUL, devido ao seu grande valor agregado: os produtos manufaturados. Com base nos dados disponibilizados pelo MDIC, buscou-se compreender qual o nível de abertura comercial brasileira em relação a produtos manufaturados destinados aos demais paísesmembros do bloco entre o período de 2000 a 2010.

Para tanto, este artigo está estruturado da seguinte maneira: compondo a primeira parte, posterior a esta introdução, apresenta-se de forma sucinta, uma descrição histórica do tema integração regional e, de forma específica, o processo integracionista do MERCOSUL. A seção dois aborda a metodologia que é composta por dois índices: o Índice de Abertura do Comércio $\left(\mathrm{O}_{\mathrm{i}}\right)$ e o Índice de Desenvolvimento do Setor Externo $\left(S X_{i}\right)$. A seção três apresenta a análise dos resultados obtidos por meio do cálculo dos referidos índices em contraste com o 
desenvolvimento da integração regional entre os países, bem como do cenário econômico internacional. Por fim, encontram-se as considerações finais as quais sumarizam o artigo.

\section{INTEGRAÇÃO REGIONAL}

Com fins de aumentar o bem-estar das nações, verificou-se, a partir do pós-guerra, uma maior tentativa de liberalização do comércio internacional, a partir da redução de barreiras tarifárias e não tarifárias no comércio entre os países (DAVID e NONNENBERG, 1997).

Em busca de estruturar e melhor entender o nível de integração regional, Balassa (1964) relaciona diferentes graus de integração, são eles: área de livre-comércio, união aduaneira, mercado comum, união econômica e monetária e ainda um estágio final caracterizado pela integração econômica total.

Baumann (2004) destaca ainda um nível a mais em relação à classificação de Balassa (1964), definido pelo simples Acordo de Preferências Comerciais - APC. Nessa situação são negociadas apenas reduções de barreiras comerciais para alguns produtos sem maiores implicações. Neste caso os países mantêm sua independência em relação ao resto do mundo.

A criação de uma Área de Livre Comércio implica eliminação de barreiras tarifárias e não tarifárias para um número generalizado de produtos. No entanto, cada país envolvido é independente em relação a sua política comercial com o resto do mundo (BALASSA, 1964).

$O$ passo seguinte ao processo de integração ocorre quando os países participantes da Área de Livre Comércio resolvem adotar uma barreira externa comum em relação aos países não participantes. Dessa maneira, atinge-se uma União Aduaneira - UA (BAUMANN, 2004).

Ao investigar os efeitos de uma UA, Viner (1950) destaca duas questões importantes no contexto de uma integração regional: a criação e o desvio de comércio. Define-se como criação de comércio o aumento de bem-estar da população, na medida em que uma UA privilegia um produtor mais eficiente em detrimento de um produtor menos eficiente (doméstico). Por sua vez, define-se como desvio de comércio e, consequentemente, a redução no bem-estar social, em função da substituição de produtores mais eficientes, os quais não fazem parte do acordo, por produtores menos eficientes que fazem parte do mesmo. 
Outro efeito a se considerar na formação de uma UA é a criação de economias de escala. Como resultado da expansão do mercado, mesmo uma nação pequena poderá superar a reduzida dimensão de seu mercado doméstico e alcançar economias de escala significativas em sua produção. Assim, para tirar vantagem de um mercado expandido e fazer frente à concorrência crescente, a formação de uma UA também estimula os investimentos, a livre mobilidade do capital e da mão de obra em nível comunitário, que tende a gerar uma utilização mais eficiente dos recursos econômicos dos países envolvidos (MACHADO, 2000).

Como analisa Machado (2000), a alteração dos preços relativos resultante da formação de uma UA pode compensar os custos gerados pelo desvio de comércio, por meio do aumento do consumo do bem produzido na região. Já a UA criadora de comércio levará ao contrário, pois parte do aumento da receita real resultante da formação da UA será diluída por meio do aumento da demanda de importações do restante do mundo.

Baumann (2004) destaca ainda que, na ocasião de uma UA, faz-se necessário o alinhamento das políticas cambiais, bem como a convergência das políticas fiscal e monetária, a fim de facilitar o alinhamento dos ciclos econômicos dos países participantes.

O nível seguinte do processo de integração regional caracterizase pela plena mobilidade dos fatores de produção entre os países, incluídos pessoas, serviços ou capitais. Constitui-se, assim, um Mercado Comum - MC (BALASSA, 1964).

A formação de um MC exige, além da coordenação das políticas fiscal, cambial e monetária, a compatibilização das legislações correlatas, como as normas trabalhistas, previdenciárias, regulação de capital, proteção aos investidores, regulação de concorrência e diversas outras. Para tanto, faz-se necessário a criação de instituições supranacionais que permitam gerir esses diversos aspectos de forma homogênea nos diversos países (BAUMANN, 2004).

O estágio posterior à instituição de um MC é a União Monetária UM. Conforme Baumann (2004), os países participantes de uma UM abrem mão dos ganhos relacionados à "Senhoriagem" derivada da emissão de moeda nacional, e assim aceitam a circulação de uma única moeda emitida por autoridade regional. Nesse caso, cita-se como exemplo de UM da atualidade o caso dos países da Zona do Euro, 
denominada União Europeia - EU. Os primeiros passos para formação desse bloco se deram em 1950 com a Comunidade Europeia do Carvão e do Aço, que foi a primeira iniciativa de unificar os países europeus. Os acordos europeus passaram pelas diversas fazes da integração regional até que, no ano 2000, com a criação do Euro (a moeda Europeia), concluiu-se a unificação econômica, tornando-a o mais forte bloco econômico da atualidade.

O último nível de integração regional é a fusão dos estados nacionais em um único Estado. Atinge-se a União Política - UP. A proximidade geográfica é característica marcante neste estágio da integração.

\begin{abstract}
A teoria da integração econômica pode ser encarada como um aspecto da economia internacional, mas também alarga o campo da teoria do comércio internacional na medida em que analisa a influência de uma fusão de mercados nacionais sobre o crescimento e examina a necessidade de coordenação das políticas econômicas no interior de uma união. Finalmente, a teoria da integração econômica deve considerar também elementos da teoria da localização. A integração de países vizinhos conduz à abolição de barreiras artificiais que impedem a atividade econômica contínua através das fronteiras nacionais e a alteração da localização da produção e as tendências de concentração e descentralização regionais daí resultantes não podem ser convenientemente discutidas sem utilizar os instrumentos da análise locacional (BALASSA, 1964, p.13).
\end{abstract}

No contexto mundial, caracterizado pela formação de grandes blocos comerciais, passa-se a analisar como se deram os acordos entre países latino-americanos que, com objetivos claros de obter benefícios por intermédio da integração econômica, culminaram na formalização do MERCOSUL.

\title{
3 MERCOSUL
}

\subsection{Dificuldades}

Conforme observado por Vizentini (2001), entre todas as tentativas de integração da América Latina, como Associação LatinoAmericana de Integração - ALADI e Associação Latino Americana de Livre Comércio - ALALC, o MERCOSUL representa o primeiro processo 
de integração regional dos países da América do Sul a conseguir alguns resultados e abrir alternativas para uma melhor inserção internacional destes países no comércio exterior.

Segundo Almeida (2002), o MERCOSUL, desde sua implementação, teve um comportamento um tanto quanto contraditório, o autor considera que esse bloco teve um inegável sucesso econômico e um nítido fracasso político, pois conseguiu, nestes anos de existência, incrementar o comércio intrarregional e criar complementaridades recíprocas entre as economias dos países-membros, mas falhou no sentido de concretizar estruturas institucionais capazes de administrar esse aumento de comércio e da interdependência, situação da qual resultam pressões e conflitos que se traduzem em disputas comerciais não resolvidas. De outro ponto de vista, o autor considera o MERCOSUL um fracasso econômico, mas um grande sucesso político na medida em que não conseguiu, até o momento, ir além de uma pequena parte dos objetivos estipulados, sobretudo no que se refere à coordenação de políticas macroeconômicas e à ambição da formação da UA que se caracterizou somente pelo seu estado virtual.

Giambiagi e Barenboim (2005) analisam que o não cumprimento da efetivação de uma Zona de Livre Comércio - ZLC completa e uma UA no MERCOSUL não são apenas o resultado das fragilidades próprias do bloco ou de suas deficiências institucionais mas também fruto da instabilidade macroeconômica que atingiu os países-membro. Segundo os autores, essa crise somente pode ser resolvida se houver um maior aprofundamento dos processos de integração entre o Brasil e a Argentina e a adoção mais flexível de metas que se comprometam com o cumprimento dos objetivos originais do MERCOSUL, os quais são cada vez mais adiados.

Para Bêrni (2001), os objetivos a serem alcançados pelo MERCOSUL passam por um caminho longo e tortuoso, pois os entraves da integração são de ordem econômica, política, cultural e social dentre os quais cita: a) a estagnação das economias integradas, pois os conflitos são mais acomodáveis em situações expansivas; b) diversidade acentuada no tamanho das economias e dos mercados nacionais; c) políticas anti-inflacionárias que exigem pesados ajustes nos diversos setores de atividade; d) elevada dívida externa; e) falta de investimentos públicos e privados em infraestrutura e nos setores produtivos; f) tarifas 
alfandegárias TEC não resolvidas; g) desconhecimento das realidades e potencialidades de cada país.

Nesse contexto, o questionamento sobre as perspectivas que se abrem para o MERCOSUL torna-se importante, seja em face às ameaças internas a sua própria integração, ou em face às ameaças externas para quem essa integração seja absorvida por outro mercado. Uma das maiores ameaças internas para o MERCOSUL está no fato de que este bloco possui grandes diferenças de magnitude e composição de sua estrutura produtiva, população e tamanho, bem como cada um de seus membros pratica suas políticas econômicas com o objetivo de combater problemas internos, mas sem coordenação com os demais países do bloco.

De acordo com Kume (1996), duas críticas poderiam ser efetuadas à estrutura tarifária do MERCOSUL; a primeira considera a existência de um número excessivo de alíquotas e a segunda refere-se à falta de uniformidade da proteção efetiva ao privilegiar a escalada da tarifa nominal para assegurar a proteção efetiva crescente em cada etapa da produção. Por outro lado, o autor reconhece que isso acomodou os interesses dos países participantes e preservou os bens intermediários, com tarifas efetivas maiores que as aplicadas para os bens de consumo final.

Sabe-se que, de acordo com a Nova Teoria do Comércio Internacional, em uma UA o efeito criação de comércio implicaria a espacialização setorial da produção, segundo a dotação de fatores existentes em cada país, gerando o desaparecimento de certas indústrias e a transferência de capital e emprego para outras. Sendo assim, a ocorrência de comércio intraindustrial induz a especialização da produção dentro de cada setor, o que significa que impactos da integração econômica sobre a distribuição das atividades econômicas entre os países não levariam ao desaparecimento de setores, mas apenas a redefinição das pautas de produção das firmas e a especialização destas em linhas específicas de produto, o que sem dúvida, minimiza o impacto reestruturante do processo de integração quando se comparam tais resultados com os previstos na teoria econômica tradicional do comércio (MACHADO, 2000).

Para Baumann (2001a), uma circunstância tem de ser primeiramente enfrentada. Como não houve implantação de políticas de compensação a setores mais sensíveis, é preciso enfrentar a realidade: 
se há vontade política de que o MERCOSUL saia de um híbrido entre ZLC e UA, é preciso a desgravação tarifária e a não proteção por parte dos setores governamentais. Se isso não acontecer, deve-se admitir que a vontade política seja fazer do MERCOSUL apenas uma ZLC. Nesse sentido, é preciso governantes com vontade política de que o MERCOSUL avance no sentido do Tratado de Assunção. Como afirma Baumann (2001a, p. 105), "[...] da mesma forma que a maior parte dos exercícios de integração regional na América Latina, também no MERCOSUL ficou claro que o processo é mais uma decisão política com resultados induzidos que uma decisão natural dos agentes econômicos". A maior parte dos contenciosos esteve sempre no comércio entre Argentina e Brasil, dado o maior peso dos fluxos comerciais destes países entre as relações sub-regionais.

Uma grande parte dos problemas enfrentados pelo MERCOSUL está relacionada com a dificuldade de alguns setores produtivos se adaptarem à nova situação de abertura comercial associado à adoção de medidas de política por parte dos governos dos países-membros, com independência entre si e quanto aos compromissos comuns (BAUMANN, 2001 b). Segundo o mesmo autor:

\footnotetext{
uma vez equacionados os temas relativos ao comércio de mercadorias, inclusive com a identificação das áreas sensíveis, a agenda negociadora teria de ampliar-se para compreender aspectos relacionados, como questão de política em relação aos consumidores, questões relacionadas ao comércio de serviços, a institucionalidade adequada para o mercado comum e muitas outras. Em outras palavras, a agenda negociadora sempre revelou algumas áreas difíceis, e tanto mais quando o próprio ritmo de crescimento das transações intra-regionais superou todas as expectativas e tornou prementes algumas dessas definições (BAUMANN, 2001 b, p.44).
}

Devido aos impasses que barram a continuidade do processo integracionista, há dúvidas no que se refere à aceitação do MERCOSUL por parte do empresariado, da sociedade e também do sistema político. Desde a origem do MERCOSUL, marcado por acordos bilaterais assinados entre Brasil e Argentina, este movimento foi marcado por duas visões convergentes, mas que tinham matrizes diferentes e uma concepção não homogênea acerca do futuro mais distante (GIAMBIAGI e MARKWALD, 2002). 
Segundo Cavalcante e Mercenier (2004), o Mercosul enfrenta problemas derivados do não cumprimento de seus objetivos principais, como a efetivação de uma ZLC completa ou uma UA integrada por normas e tarifas verdadeiramente comuns. Esses problemas não são apenas resultado de fragilidades do bloco ou de deficiências institucionais, mas também consequência das instabilidades macroeconômicas que atingiram os países-membros, principalmente Brasil e Argentina.

Diferentes visões quanto aos objetivos e abrangência do MERCOSUL tende a dificultar o progresso das negociações. A partir do momento em que a sociedade e o governo tiverem uma meta a seguir, o MERCOSUL cumprirá seus objetivos, seguindo os Princípios do Regionalismo Aberto. O MERCOSUL, que tinha como objetivo inicial de se tornar, como o próprio nome diz, um mercado comum, após mais de vinte anos de existência encontra-se entre uma ZLC e uma UA.

\subsection{As Relações Comerciais}

Conforme levantado por Vasconcelos (2000), a composição das pautas de exportações e importações brasileiras com destino a paísesmembros do MERCOSUL, entre o período de 1990 a 1998, é caracterizado pela crescente importância de produtos industrializados.

Cabe destacar que, desde o momento de sua criação o bloco possui basicamente objetivos econômicos. Atualmente, apesar de estarem sendo tratados novos assuntos dentro do bloco, a questão econômica e comercial continua sendo o principal objetivo.

Segundo Baumann (2001b), o principal efeito verificado com o desenvolver do bloco é o admirável aumento do comércio desde 1990. O autor ainda ressalta a ocorrência de um grande aumento do investimento direto entre os países-membros do MERCOSUL.

De outro ponto de vista, Baumann (2001b) destaca algumas dificuldades existentes no processo integracionista relacionado ao MERCOSUL:

uma vez equacionados os temas relativos ao comércio de mercadorias, inclusive com a identificação das áreas sensíveis, a agenda negociadora teria de ampliar-se para compreender aspectos relacionados, como questão de política em relação aos consumidores, questões relacionadas ao comércio de serviços, 
a institucionalidade adequada para o mercado comum e muitas outras. Em outras palavras, a agenda negociadora sempre revelou algumas áreas difíceis, e tanto mais quando o próprio ritmo de crescimento das transações intrarregionais superou todas as expectativas e tornou prementes algumas dessas definições (BAUMANN, 2001 b, p.44).

Segundo Becker (2002), para um país em que a indústria possui certo peso, como no Brasil, o MERCOSUL possui importância estratégica, à medida que aumenta os mercados para os produtos e fortalece o país como uma "potência média".

Conforme Bouzas (2001) uma das explicações para as diferentes fases atravessadas pelos países-membros do bloco advém dos divergentes interesses pelos quais os países foram motivados a se integrar. Como exemplo de sua teoria, o autor cita características dos dois maiores membros do bloco, ou seja, o Brasil tinha como objetivo "ampliar seu papel em nível internacional", já a Argentina buscava primeiramente "ganhos em termos de comércio". Dessa forma os objetivos divergentes entre os países tornaram-se empecilhos ao processo de integração.

Ainda em relação ao estudo de Bouzas (2001), é necessário um mecanismo para lidar de forma apropriada com os problemas da liberalização do comércio, para que os setores mais sensíveis não sofram com a retirada das salvaguardas.

De fato, o MERCOSUL oferece ao Brasil a possibilidade de se tornar líder de uma região com um PIB da ordem de grandeza de US\$ 1 trilhão; sem conflitos étnicos, de fronteira, religiosos, histórico ou culturais; com sistemas financeiros relativamente desenvolvidos; uma tradição capitalista de décadas; um parque industrial de porte razoável; consumo de massa; e uma considerável demanda reprimida, visto se tratar de uma região com uma renda per capita média, porém com bolsões de pobreza expressivos [...]. Se bem aproveitado, trata-se de um conjunto de potencialidades que fazem da região uma das áreas do mundo mais promissoras em uma perspectiva de longo prazo, em termos de crescimento econômico (GIAMBIAGI e MARKWALD, 2002, p.5).

Segundo a visão de Giambiagi e Markwald (2002), para que isso ocorra, faz-se necessário que brasileiros e argentinos parem de 
desconfiar uns dos outros, e que a opinião pública julgue o MERCOSUL benéfico para ambos os países.

De acordo com Sica (2004), ex-secretário de Indústria, Comércio e Mineração da Argentina, um dos problemas no comércio bilateral entre Brasil e Argentina é a disparidade entre os dois países, fazendo com que o Brasil acabe exportando produtos com maior valor agregado, e a Argentina, com menos valor agregado. De acordo com o autor, parte dessa disparidade foi causada pelas crises ocorridas em ambos os países, além das diferenças macroeconômicas e do fato de o Brasil receber maior Investimento Externo Direto - IED. Nas palavras do autor, "O Brasil, de fato, consolidou-se como fornecedor de produtos de maior valor agregado e com claro viés industrial"(SICA, 2004, p.12).

Como podemos observar nos dados do MDIC, dispostos na Tabela 1, a composição das exportações brasileiras com destino aos paísesmembros do MERCOSUL é formada, em sua grande maioria, por produtos Industrializados. Durante todo o período em análise, os produtos Manufaturados participaram, em média, com 91,3\% do total exportado, enquanto os produtos básicos tiveram média de 5,6\%, seguidos pelos Semimanufaturados, cerca de 3,1\% em média. Estes dados reforçam a ideia de Sica (2004) de que o Brasil exporte produtos com maior valor agregado contribuindo para o equilíbrio da balança comercial. Vale ressaltar que a importância dos produtos manufaturados na economia de um país se dá pelo valor agregado que o produto adquire.

Brum (2002) afirma que o Brasil tem se especializado em exportar produtos industrializados e importar produtos agropecuários do interior do Bloco. Já a Argentina realiza o processo inverso. Ratificando essa afirmação, Bandeira (1987) afirma que as relações entre o Brasil e a Argentina sempre se caracterizaram pela ambivalência, em que tendências para o conflito ou para cooperação se acentuavam, conforme as articulações econômicas e políticas das correntes que eventualmente detivessem o poder em cada um dos países (BANDEIRA, 1987, apud CARDOSO, 2008, p. 27) ${ }^{1}$.

Tabela 1. Exportações brasileiras por fator agregado - MERCOSUL (US\$

\footnotetext{
1 BANDEIRA, L. A. M. O eixo Argentina-Brasil: o processo de integração da América Latina. Brasília, DF: ONB, 1987. 118 p.
}

Redes (St. Cruz Sul, Online), v. 20, nº 3 - Suplemento, p. 401 - 425, set./dez. 2015412 
em milhões FOB)

\begin{tabular}{c|c|c|c|c|c|c|c}
\hline & & & \multicolumn{3}{|c|}{ Industrializados } & \\
\cline { 5 - 7 } Ano & $\begin{array}{c}\text { Básicos } \\
(\text { A) }\end{array}$ & Part. \% & $\begin{array}{c}\text { Semi } \\
\text { manufaturados } \\
(\text { (B) }\end{array}$ & Part. \% & $\begin{array}{c}\text { Manufaturados } \\
(\mathrm{C})\end{array}$ & Part. \% & $\begin{array}{c}\text { Total } \\
(\mathrm{A}+\mathrm{B}+\mathrm{C})\end{array}$ \\
\hline 2000 & 453 & 5,9 & 193 & 2,5 & 7.072 & 91,6 & 7.718 \\
2001 & 439 & 6,9 & 209 & 3,3 & 5.707 & 89,8 & 6.355 \\
2002 & 279 & 8,4 & 155 & 4,7 & 2.870 & 86,9 & 3.303 \\
2003 & 388 & 6,8 & 203 & 3,6 & 5.072 & 89,6 & 5.662 \\
2004 & 439 & 4,9 & 329 & 3,7 & 8.138 & 91,4 & 8.906 \\
2005 & 551 & 4,7 & 352 & 3,0 & 10.804 & 92,3 & 11.707 \\
2006 & 653 & 4,7 & 457 & 3,3 & 12.832 & 92,0 & 13.941 \\
2007 & 710 & 4,1 & 497 & 2,9 & 16.115 & 93,0 & 17.322 \\
2008 & 1.074 & 4,9 & 642 & 3,0 & 20.002 & 92,1 & 21.718 \\
2009 & 617 & 3,9 & 297 & 1,9 & 14.886 & 94,2 & 15.800 \\
2010 & 1.440 & 6,4 & 559 & 2,5 & 20.563 & 91,1 & 22.563 \\
\hline
\end{tabular}

Fonte: MDIC (2013).

Apesar de tudo, há um grande interesse brasileiro de que ocorra crescimento na indústria Argentina:

o chanceler brasileiro, Celso Amorim, defendeu ontem que o bloco e a OMC encontrem uma solução para ajudar a indústria Argentina. Mas indicou que o momento não é de endurecer posições e todos precisam mostrar flexibilidade. Amorim esteve reunido com o chanceler da Argentina, Jorge Taina, durante viagem a Doha para encontro da ONU (O Estado de São Paulo, $01 / 12 / 2008)$.

Contudo segundo a Comissão Econômica para a América Latina e o Caribe - CEPAL (2002), muitos dos avanços alcançados pelo MERCOSUL não eram esperados por grande parte dos analistas que tratam do tema. Ou seja, além do destacável aumento no volume de comércio, aumentaram substancialmente as inversões dos países na região, com foco em setores industriais.

Baumann (2001) destaca que é admirável o aumento do comércio desde 1990, pois esse aumento refletiu no crescimento do "peso relativo das transações intrarregionais nos fluxos totais" de comércio. 0 autor ressalta ainda que o MERCOSUL serviu como aprendizado para os países, no sentido de que é mais vantajoso negociar em bloco do que sozinho. 
Com base nos dados do MDIC (2013), dispostos na Tabela 2, fazse uma comparação entre o crescimento total das exportações e importações brasileiras com as destinadas aos países-membros do MERCOSUL. O volume das exportações com destino ao MERCOSUL cresceu cerca de $192 \%$ durante o período, enquanto as importações cresceram 113,1 \%. Com relação às exportações totais, o crescimento foi de $266,3 \%$ nas exportações e 225,4 \% nas importações.

Tabela 2. Intercâmbio comercial Brasil e países-membros do MERCOSUL 2000 a 2010

\begin{tabular}{c|c|c|c|c|c|c|c|c}
\hline \multirow{2}{*}{ Ano } & \multicolumn{4}{|c|}{ Exportações UU\$ } & \multicolumn{4}{c}{ Importações UU\$ } \\
\cline { 2 - 9 } & Total* & $\begin{array}{c}\text { Cresc } \\
. \%\end{array}$ & Mercosul & $\begin{array}{c}\text { Cresc. } \\
\%\end{array}$ & Total* & $\begin{array}{c}\text { Cresc. } \\
\%\end{array}$ & Mercosul & $\begin{array}{c}\text { Cresc. } \\
\%\end{array}$ \\
\hline 2000 & 55.119 & 0,00 & 7.740 & 0,00 & 55.851 & 0,00 & 7.796 & 0,00 \\
2001 & 58.287 & 0,06 & 6.374 & $-0,18$ & 55.602 & 0,00 & 7.010 & $-0,10$ \\
2002 & 60.439 & 0,04 & 3.319 & $-0,48$ & 47.243 & $-0,15$ & 5.612 & $-0,20$ \\
2003 & 73.203 & 0,21 & 5.684 & 0,71 & 48.326 & 0,02 & 5.685 & 0,01 \\
2004 & 96.677 & 0,32 & 8.935 & 0,57 & 62.836 & 0,30 & 6.390 & 0,12 \\
2005 & 118.529 & 0,23 & 11.746 & 0,31 & 73.600 & 0,17 & 7.054 & 0,10 \\
2006 & 137.807 & 0,16 & 13.986 & 0,19 & 91.351 & 0,24 & 8.967 & 0,27 \\
2007 & 160.649 & 0,17 & 17.354 & 0,24 & 120.617 & 0,32 & 11.625 & 0,30 \\
2008 & 197.942 & 0,23 & 21.737 & 0,25 & 172.985 & 0,43 & 14.934 & 0,28 \\
2009 & 152.995 & $-0,23$ & 15.829 & $-0,27$ & 127.722 & $-0,26$ & 13.107 & $-0,12$ \\
2010 & 201.915 & 0,32 & 22.602 & 0,43 & 181.768 & 0,42 & 16.620 & 0,27 \\
\hline
\end{tabular}

Fonte: MDIC (2013).

Nota: * - US\$ em milhões FOB.

Para melhor visualizar os dados da Tabela 2, é exibida, no Gráfico 1, a evolução das exportações em contraste com a evolução das importações brasileiras com os países-membros do MERCOSUL. Verifica-se que desde a criação do bloco, no início da década de 1990 , as relações comerciais apresentam crescimento. Os únicos períodos de queda foram nos anos de 1999 e 2002, devido à chamada crise do bloco, e no ano de 2009, resultado da crise do Subprime ocorrida no ano anterior. Tanto em uma como na outra, o comércio voltou a se recuperar logo em seguida, atingindo patamares maiores que os anteriores. 
Gráfico 1. Exportações/Importações brasileiras para o MERCOSUL (US\$ em Bilhões FOB)

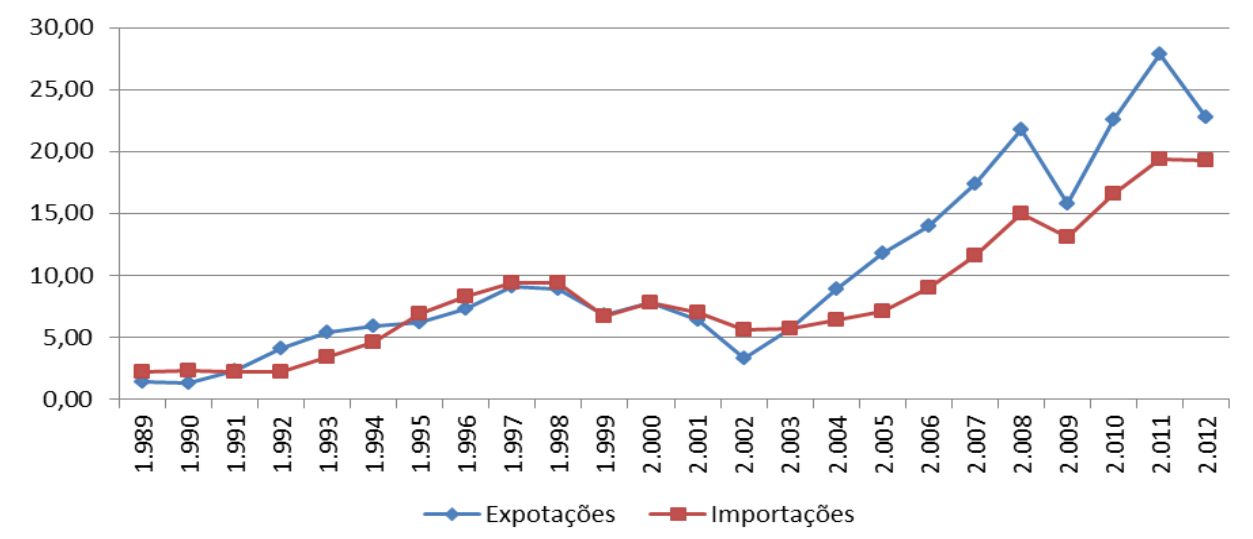

Fonte: MDIC (2013).

Baumann (2011) enfatizou ainda que o processo de aproximação formal das economias do Cone Sul possibilitou crescimento considerável do volume transacionado. Os resultados obtidos mais recentemente são fortemente influenciados pelo desempenho das exportações totais, em grande medida determinados pela variação dos preços de exportação, o que afetou o valor exportado total.

\footnotetext{
As exportações entre os quatro países aumentaram quase seis vezes em valor, entre o início da década de 1990 e o fim da década seguinte. Isso supera o aumento de pouco mais de quatro vezes no total das exportações mundiais no mesmo período. Houve, portanto, ganho relativo em termos de aumento do grau de interação entre as quatro economias (BAUMANN, 2011, p.10).
}

Nesse sentido, Vizentini (2007) acredita que ocorreram tanto ganhos econômicos e comerciais com o processo integracionista do MERCOSUL, assim como no campo político. O autor aponta que fica cada vez mais claro que o MERCOSUL tem como objetivo implícito a manutenção de uma base industrial dentro de seu território, objetivando criar condições para que empresas transnacionais permaneçam nos países integrantes do bloco.

\section{METODOLOGIA}


Com o fim de delinear os objetivos deste estudo, foram utilizados índices que medem a abertura comercial e o desempenho do setor externo. Para tanto, aplicou-se o Índice de Abertura do Comércio - $O_{i}$, exposto por Edwards (1998), a fim de analisar a abertura comercial com relação a produtos manufaturados brasileiros destinados ao MERCOSUL. Em seguida, aplicou-se o Índice de Desenvolvimento do Setor Externo (SX $X_{i}$ apresentado por Ruiz (2004), com o objetivo de analisar o desempenho da economia brasileira também em relação a produtos manufaturados brasileiros com destino ao MERCOSUL.

Para o cálculo dos índices apresentados, foram utilizados dados de Exportação (X) e Importação (M), disponibilizados pelo MDIC e dados de PIB e de IED, ambos disponibilizados pelo Instituto Brasileiro de Geografia e Estatística - IBGE.

O MDIC agrupa os produtos em duas grandes classes, levando-se em consideração o maior ou o menor valor agregado adicionado a cada produto, são eles: produtos básicos e produtos industrializados. Os produtos industrializados, por sua vez, são divididos em semimanufaturados: aqueles que passaram por algum tipo de transformação; e manufaturados: aqueles de alto valor agregado, caracterizado por utilização de muita tecnologia.

O presente trabalho elencou dados sobre ambos os produtos, semimanufaturados e manufaturados, no entanto, deu-se maior importância aos produtos manufaturados visto que são estes os que geram maior renda ao país exportador.

\subsection{0 Índice de Abertura do Comércio $\left(\mathrm{O}_{\mathrm{i}}\right)$}

De acordo com Edwards (1998), o O $O_{i}$ estuda a relação entre o volume total de comércio $(X+M)$ e o PIB. Este índice mede o nível de liberalização do comércio e a orientação da política comercial de uma economia. Possui como objetivo apontar qual a participação do setor externo sobre o produto doméstico, ou seja, quão aberta ao mercado mundial está uma economia. Seu valor varia de 0 a $100 \%$, e quanto mais perto de $100 \%$, maior o grau de abertura da economia analisada.

Este índice é definido por:

$$
O_{i}=\frac{(X+M) \cdot 100 \%}{P I B}
$$

Em que:

Redes (St. Cruz Sul, Online), v. 20, nº 3 - Suplemento, p. 401 - 425, set./dez. 2015416 
$\mathrm{X}=$ Exportações

$M=$ Importações

\subsection{O Índice de Desenvolvimento do Setor Externo (SX}

$\mathrm{O} S X_{i}$ é um forte parceiro do $\mathrm{O}_{\mathrm{i}}$. A diferença entre esses dois indicadores é que o $S X_{i}$ acrescenta à taxa de crescimento do valor absoluto comércio (ou valor relativo), representada pela Taxa de Variação do Comércio ( $\Delta \mathrm{VC}=\Sigma$ Taxa de Variação da Exportação mais $\Sigma$ Taxa de Variação da Importação), a Taxa de Variação do Investimento Estrangeiro Direto $(\triangle \mathrm{IED})$. O SX é representado por dois crescimentos específicos, a Taxa de Variação do Volume Comércio $(\Delta \mathrm{VC})$ e a Taxa de Variação do Montante de Investimento Estrangeiro Direto ( $\triangle \mathrm{IED})$. O volume de comércio é igual à soma do fluxo de exportação (FOB) mais fluxo de importação (CIF). O investimento é representado pela variação do montante entre dois anos. O cálculo do $S X_{i}$, segundo Ruiz (2004), requer os quatro passos detalhados a seguir:

$1{ }^{\circ}$ Passo: Taxa de Variação do Volume do Comércio ( $\triangle V C$ ) - é a diferença entre o Volume do Comércio de um dado ano $(X+M)_{t+1}$ e o Volume do Comércio do ano anterior $(X+M)_{t}$ dividido pelo Volume do Comércio do ano anterior $(\mathrm{X}+\mathrm{M})_{\mathrm{t}}$. Tem-se:

$$
\Delta V C=\frac{(X+M)_{t+1}-(X+M)_{t}}{(X+M)_{t}}
$$

$2^{\circ}$ Passo: Taxa de Variação do Investimento Estrangeiro Direto (IIED) - é a diferença entre o Volume do Investimento Estrangeiro Direto de um dado ano (IED) $t+1$ e o Investimento Direto Estrangeiro do ano anterior $(\mathrm{IED})_{\mathrm{t}}$, dividido pelo Investimento Estrangeiro Direto do ano anterior (IED)t. Tem-se:

$$
\Delta I E D=\frac{(I E D)_{t+1}-(I E D)_{t}}{(I E D)_{t}}
$$

$3^{\circ}$ Passo: Taxa de Variação do Produto Interno Bruto $(\triangle P I B)$ - é igual ao $\mathrm{PIB}$ de um dado ano $(\mathrm{PIB})_{\mathrm{t}+1}$ menos o do ano anterior $(\mathrm{PIB})_{\mathrm{t}}$, dividido pelo PIB do ano anterior (PIB) t. Tem-se:

$$
\Delta P I B=\frac{(P I B)_{t+1}-(P I B)_{t}}{(P I B)_{t}}
$$

$4^{\circ}$ Passo: Índice de Desenvolvimento do Setor Externo (SX $X_{i}$ - é igual à soma Taxa de Variação do Volume de Comércio $(\Delta \mathrm{V} C)$ e da Taxa de 
Variação do Investimento Estrangeiro Direto ( $\Delta \mathrm{IED}$ ) dividido pela Taxa de Variação do Produto Interno Bruto $(\triangle \mathrm{PIB})$. Tem-se:

$$
S X_{i}=\frac{(\Delta V C+\Delta I E D) \cdot 100 \%}{\Delta P I B}
$$

Quanto à análise desse índice, seguem-se os seguintes parâmetros:

- Alta vulnerabilidade - Sempre que a variável principal do comércio $\left(E S_{i}\right)^{2}$ e $\triangle \mathrm{PIB}$ estão localizadas nos seguintes parâmetros $\left(+E S_{I} / \triangle P I B\right)$ ou $\left(-E S_{I} / \triangle P I B\right)$ ou $\left(E S_{I}=0 / \triangle P I B=0\right)$, então, o $\left(S X_{i}\right)$ pode ser classificado dentro da categoria de alta vulnerabilidade. A alta vulnerabilidade indica que o $E S_{I}$ e o PIB possuem mudanças na mesma direção e podem estar fortemente ligados. O que significa que o PIB do país é fortemente influenciado pelos acontecimentos do setor externo.

- Vulnerabilidade normal - Sempre que $E S_{I}$ e $\triangle$ PIB estão localizados dentro destes parâmetros $\left(+E S_{I} /-\triangle P I B\right)$ ou $\left(+E S_{I} / \triangle P I B=0\right)$, então o $S X_{i}$ pode ser classificado dentro da categoria de vulnerabilidade normal. A categoria de vulnerabilidade normal pode indicar que $E S_{I}$ cresce mais rapidamente que o PIB, o que mostra que, apesar do setor externo depender da tendência do comércio mundial, não pode afetar muito o PIB.

- Baixa vulnerabilidade - Sempre que $E S_{I}$ e $\triangle P I B$ estão localizados dentro destes parâmetros $\left(-E S_{I} /+\triangle P I B\right)$ ou $\left(-E S_{I} / \triangle P I B=0\right)$ ou $\left(E S_{I}=0 /+\triangle P I B\right)$ ou $\left(E S_{I}=0 /-\triangle P I B\right) ;$ então, o $S X_{i}$ pode ser classificado dentro da categoria de baixa vulnerabilidade. A categoria de baixa vulnerabilidade pode mostrar como $E S_{i}$ cresce lentamente em relação ao crescimento de PIB, o que mostrará claramente que o setor externo não é o fator principal que afeta o crescimento do PIB de qualquer setor.

O Quadro 1 apresenta uma síntese da análise do Índice de Desenvolvimento do Setor Externo $\left(\mathrm{SX}_{\mathrm{i}}\right)$, tornando possível a classificação de cada valor calculado em termos de Vulnerabilidade e Performance.

Quadro 1. Análise do Índice de Desenvolvimento do Setor Externo (SX)

\begin{tabular}{|c|c|c|c|}
\hline & $+\Delta \mathrm{PIB}$ & $-\Delta \mathrm{PIB}$ & $\Delta \mathrm{PIB}=0$ \\
\hline \multirow{2}{*}{$+\mathrm{ES}_{\mathrm{i}}$} & Nível -1.1 & Nível -1.2 & Nível -1.3 \\
& Alta Vulnerabilidade & Vulnerabilidade Normal & Vulnerabilidade Normal \\
\hline
\end{tabular}

\footnotetext{
2 Sendo a $E S_{i}=\Delta V C$ (Variação do Volume de Comércio) + $\Delta \mathrm{IED}$ (Variação do Investimento Estrangeiro Direto).
} 
Fagner Mendonça Avelar, Cristiano Stamm, Carlos Alberto Gonçalves Junior

\begin{tabular}{|c|c|c|c|}
\hline & $\begin{array}{c}+\mathrm{ESi} /+\Delta \mathrm{PIB}=+\mathrm{SX}_{\mathrm{i}} \\
\text { Performance Aceitável }\end{array}$ & $\begin{array}{c}+\mathrm{ES}_{\mathrm{i}} /-\Delta \mathrm{PIB}=-\mathrm{SX}_{\mathrm{i}} \\
\text { Performance Fraca }\end{array}$ & $\begin{array}{c}+\mathrm{ES}_{\mathrm{i}} / 0=\mathrm{SXi}=\infty \\
\text { Performance Aceitável }\end{array}$ \\
\hline$-\mathrm{ES}_{\mathrm{i}}$ & $\begin{array}{c}\text { Nível }-2.1 \\
\frac{\text { Baixa Vulnerabilidade }}{-\mathrm{ESi} /+\Delta \mathrm{PIB}=-\mathrm{SX}_{\mathrm{i}}} \\
\text { Performance Fraca }\end{array}$ & $\begin{array}{c}\text { Nível }-2.2 \\
\text { Alta Vulnerabilidade } \\
-\mathrm{ES}_{\mathrm{i}} /-\Delta \mathrm{PIB}=+\mathrm{SX}_{\mathrm{i}} \\
\text { Performance Aceitável }\end{array}$ & $\begin{array}{c}\text { Nível }-2.3 \\
\text { Baixa Vulnerabilidade } \\
-\mathrm{ES}_{\mathrm{i}} /+\Delta \mathrm{PIB}=-\mathrm{SX}_{\mathrm{i}}=\infty \\
\text { Performance Fraca }\end{array}$ \\
\hline$E S i=0$ & $\begin{array}{c}\text { Nível }-3.1 \\
\text { Baixa Vulnerabilidade } \\
0 /+\Delta \mathrm{PIB}=\mathrm{SX}_{\mathrm{i}}=0 \\
\text { Performance Fraca }\end{array}$ & $\begin{array}{c}\text { Nível }-3.2 \\
\text { Baixa Vulnerabilidade } \\
0 /-\Delta \mathrm{PIB}=\mathrm{SX}_{\mathrm{i}}=0 \\
\text { Performance Fraca }\end{array}$ & $\begin{array}{c}\text { Nível }-3.3 \\
\text { Alta Vulnerabilidade } \\
0 / 0=S X_{i}=0 \\
\text { Performance Fraca }\end{array}$ \\
\hline
\end{tabular}

Fonte: Adaptado de Ruiz (2004).

Nota: $(-)=$ Negativo, $(+)=$ Positivo, $(0)=$ Nulo

Uma visão sintetizada da comparação dos três índices que foram abordados na pesquisa está disposta no Quadro 2. O Quadro demonstra as principais funções, vantagens e desvantagens de cada índice utilizado, buscando, assim, atingir os objetivos propostos pelo trabalho.

Quadro 2. Comparação dos dois índices $O_{i}$ e $S X_{i}$

\begin{tabular}{|c|c|c|c|}
\hline Índices & Função & Vantagens & Desvantagens \\
\hline $\begin{array}{c}\text { Índice de } \\
\text { Abertura (Oi) }\end{array}$ & $\begin{array}{l}\text { Medir o nível de } \\
\text { liberalização } \\
\text { comercial e a } \\
\text { tendência da } \\
\text { política comercial }\end{array}$ & $\begin{array}{l}\text { Dá a ideia geral de quão } \\
\text { aberta uma economia } \\
\text { está no comércio } \\
\text { internacional }\end{array}$ & $\begin{array}{c}\text { Observação } \\
\text { limitada ao nível } \\
\text { de abertura do } \\
\text { mercado para a } \\
\text { perspectiva do } \\
\text { comércio } \\
\text { internacional }\end{array}$ \\
\hline $\begin{array}{c}\text { Índice de } \\
\text { Desenvolvimento } \\
\text { do Setor Externo } \\
\qquad\left(\mathrm{SX}_{\mathrm{i}}\right)\end{array}$ & $\begin{array}{c}\text { Medir a } \\
\text { liberalização do } \\
\text { comércio e a } \\
\text { mobilidade de } \\
\text { investimentos, } \\
\text { simultaneamente }\end{array}$ & $\begin{array}{l}\text { Observa o desempenho } \\
\text { do setor externo e do } \\
\text { setor financeiro a partir } \\
\text { das perspectivas } \\
\text { comerciais e financeiras, } \\
\text { simultaneamente }\end{array}$ & $\begin{array}{l}\text { Dificuldade no } \\
\text { controle da } \\
\text { mobilidade do } \\
\text { IED no curto } \\
\text { prazo }\end{array}$ \\
\hline
\end{tabular}

Fonte: Adaptado de Ruiz (2004).

\section{RESULTADOS E DISCUSSÕES}

Os índices calculados utilizando-se das exportações e importações totais de produtos manufaturados entre o Brasil e os demais países-membros do MERCOSUL estão dispostos na Tabela 3. Conforme visto anteriormente, $\mathrm{o}$ Índice $\mathrm{O}_{i}$ estuda a relação entre $\mathrm{O}$ 
volume total de comércio $(\mathrm{X}+\mathrm{M})$ e o $\mathrm{PIB}$, medindo o nível da liberalização do comércio, bem como a orientação da política comercial de um país. Seu objetivo é mostrar quão aberta é uma economia ao mercado internacional, neste caso, o quão aberta é a economia do Brasil em relação aos países que compõem o MERCOSUL. Quanto maior o valor apresentado no resultado do cálculo do índice, melhor é a avaliação que se faz do desempenho do setor externo. No que se refere ao índice de Desenvolvimento do Setor Externo SX, este "novo" índice inserido na análise do comércio internacional procura mostrar simultaneamente o nível de liberalização do comércio e a mobilidade de investimentos.

De acordo com os dados, percebeu-se uma relativa estabilidade quanto aos valores calculados para o índice de abertura comercial $\left(\mathrm{O}_{\mathrm{i}}\right)$. $\mathrm{O}$ índice apresentou uma média de 1,7\% no período, sendo que o ano de maior abertura ocorreu em 2001 , cerca de $2,0 \%$ e o de menor abertura foi o ano de 2002, aproximadamente 1,3\%.

$\mathrm{Na}$ maior parte dos anos em análise, o Brasil apresentou um nível de Alta Vulnerabilidade expresso pelo $\mathrm{SX}_{\mathrm{i}}$, o que significa que o volume de comércio, representado pela exportação e importação de produtos manufaturados, a variação do PIB e o IED se moveram-se na mesma direção, podendo, portanto, estar fortemente relacionados. Com exceção dos anos de 2003 e 2009, a performance do ES se manteve em níveis aceitáveis.

As exportações e importações dos países-membros variaram de forma diferenciada nos primeiros anos após a criação do MERCOSUL (NONNENBERG E MESENTIER, 2011). No entanto, segundo o autor, as exportações dos quatro países só começam a crescer mais vigorosamente após os eventos econômicos internacionais do início última década, em grande parte devido ao forte aumento dos preços das commodities.

Os problemas econômicos de 2002 refletiram, em parte, numa crise de desconfiança associada à incerteza em torno do que ocorreria com a política econômica a partir de 2003 , com a posse do novo governo. O índice de abertura comercial, com relação a produtos manufaturados, apresentou seu menor valor em todo o período analisado, 1,3\% de abertura. Quanto ao $\mathrm{SX}_{\mathrm{i}}$ o nível de vulnerabilidade foi classificado como Alto dado que tanto variação do IED quanto a variação do comércio de produtos manufaturados retraíram-se no ano de 2002. 
Esse fato sugere que a variação do PIB (retração de 4\%) está fortemente relacionada a esses dois indicadores (IED e Variação do Comércio).

Ainda com relação ao ano de 2002, verifica-se a iminência de um ano ruim para a economia brasileira a partir da análise de outros três indicadores econômicos. Primeiro, o risco país, medido pelo Standard \& Poor's $s^{3}$, atingiu mais de 2000 pontos-base em outubro de 2002 , depois de se encontrar em pouco mais de 700 pontos em março do mesmo ano. Segundo, a taxa de câmbio, divulgada belo Banco Central, que em março de 2002, fechara em $R \$ 2,32 /$ US $\$ 1,00$, chegou a $\mathrm{R} \$ / 3,89 \mathrm{US} \$ 1,00$ no final de setembro. E terceiro, a expectativa da inflação para 2003, medida pelo Índice Nacional de Preços ao Consumidor Amplo - IPCA, em 1 1\%.

De outro ponto de vista, Moreira e Milhomem (2010) destacam que, a partir dos últimos meses de 2002, as exportações do Brasil para a Argentina cresceram em um ritmo bastante elevado. Esse fato reflete a rápida aceleração da Argentina logo após a saída da recessão. Nas palavras do autor "A Argentina foi o país que mais cresceu como destino das exportações brasileiras durante os últimos sete anos" (MOREIRA e MILHOMEM, 2010, p. 16). No entanto o índice de desenvolvimento do setor externo (SX $\left.X_{i}\right)$ apresentou performance fraca no ano de 2003 , tendo em vista queda significativa no volume de IED (retração de $34 \%$ em relação a 2002). Destaca-se, ainda, que os fatores relatados anteriormente, em conjunto com o decreto da moratória da Argentina em 2001 e o fim do regime de conversibilidade, também da Argentina, em 2002, contribuíram para o baixo desempenho da economia brasileira no ano de 2003.

\footnotetext{
${ }^{3}$ Standard \& Poor's (S\&P) é uma divisão do grupo McGraw-Hill que publica análises e pesquisas sobre bolsas de valores e títulos.
} 
A Liberalização Comercial Brasileira vista no âmbito do Mercosul a partir dos produtos...

Tabela 3. Aplicação dos Índices: Abertura de Comércio e Desenvolvimento do Setor Externo - Brasil (bilhões US\$)

\begin{tabular}{|c|c|c|c|c|c|c|c|c|c|c|c|}
\hline & 2000 & 2001 & 2002 & 2003 & 2004 & 2005 & 2006 & 2007 & 2008 & 2009 & 2010 \\
\hline Exportação & 7,07 & 5,71 & 2,87 & 5,07 & 8,14 & 10,80 & 12,83 & 16,11 & 20,00 & 14,89 & 20,56 \\
\hline Var. Export. & 0,00 & $-0,19$ & $-0,50$ & 0,77 & 0,60 & 0,33 & 0,19 & 0,26 & 0,24 & $-0,26$ & 0,38 \\
\hline Importação & 4,54 & 4,44 & 3,50 & 3,43 & 4,44 & 5,26 & 6,67 & 8,67 & 11,53 & 10,09 & 13,08 \\
\hline Var. Import. & 0,00 & $-0,02$ & $-0,21$ & $-0,02$ & 0,29 & 0,18 & 0,27 & 0,30 & 0,33 & $-0,12$ & 0,30 \\
\hline Comércio & 11,61 & 10,14 & 6,37 & 8,50 & 12,58 & 16,06 & 19,50 & 24,79 & 31,53 & 24,98 & 33,64 \\
\hline$\Delta \mathrm{VC}$ & 0,00 & $-0,13$ & $-0,37$ & 0,34 & 0,48 & 0,28 & 0,21 & 0,27 & 0,27 & $-0,21$ & 0,35 \\
\hline IED & 32,63 & 19,68 & 15,63 & 10,35 & 18,76 & 15,52 & 18,95 & 35,33 & 43,58 & 26,76 & 49,28 \\
\hline Var. IED & 0,00 & $-0,40$ & $-0,21$ & $-0,34$ & 0,81 & $-0,17$ & 0,22 & 0,86 & 0,23 & $-0,39$ & 0,84 \\
\hline PIB & 641,79 & 502,26 & 483,67 & 568,76 & 677,04 & 903,02 & 1096,25 & 1410,97 & 1623,69 & 1697,95 & 2178,24 \\
\hline Var. PIB & 0,00 & $-0,22$ & $-0,04$ & 0,18 & 0,19 & 0,33 & 0,21 & 0,29 & 0,15 & 0,05 & 0,28 \\
\hline $\mathrm{ES}_{\mathrm{i}}$ & 0,00 & $-0,52$ & $-0,58$ & 0,00 & 1,29 & 0,10 & 0,44 & 1,14 & 0,51 & $-0,59$ & 1,19 \\
\hline Performance $\left(\mathrm{ES}_{\mathrm{i}}\right)$ & & Aceitável & Aceitável & Fraca & Aceitável & Aceitável & Aceitável & Aceitável & Aceitável & Fraca & Aceitável \\
\hline$S X_{i}$ & 0,00 & 240,57 & 1561,47 & $-1,16$ & 678,23 & 31,14 & 203,44 & 395,65 & 335,27 & $-1298,43$ & 420,22 \\
\hline $\mathrm{O}_{\mathrm{i}}$ & 1,81 & 2,02 & 1,32 & 1,50 & 1,86 & 1,78 & 1,78 & 1,76 & 1,94 & 1,47 & 1,54 \\
\hline Vulnerabilidade $\left(S X_{i}\right)$ & & Alta & Alta & Baixa & Alta & Alta & Alta & Alta & Alta & Baixa & Alta \\
\hline Nível Vulnerabilidade & & 2.2 & 2.2 & 3.1 & 1.1 & 1.1 & 1.1 & 1.1 & 1.1 & 2.1 & 1.1 \\
\hline
\end{tabular}

Fonte: Dados da pesquisa (2013). 
O estudo de Nonnemberg e Mesentier (2011) buscou verificar, a partir da integração regional que formou o MERCOSUL, o crescimento da participação de produtos classificados por grau de intensidade tecnológica entre os países-membros do bloco. Verificou-se que, a partir de 2003, os produtos menos intensivos em tecnologia, exportados pelo Brasil, passaram a dar lugar a produtos com maior intensidade tecnológica. Em suma, o estudo conclui que, apesar dos países-membros do bloco terem ampliado a intensidade tecnológica dos produtos exportados para os parceiros do bloco, o mesmo não ocorreu com os produtos exportados para fora do MERCOSUL, estas, portanto, foram pouco afetadas pela intensificação tecnológica resultante da integração regional.

No período que se inicia em 2004 e segue até o ano de 2008, o Brasil atravessa uma fase de estabilidade e crescimento. O PIB, o IED e a Variação do Comércio tiveram variações positivas. Os resultados obtidos no calculo do $\mathrm{SX}_{\mathrm{i}}$ apresentaram um nível de vulnerabilidade alta, demonstrando que, de fato, os indicadores se moveram na mesma direção, podendo estar diretamente relacionados. Nota-se, portanto, pela performance do $E S_{i}$, que o Brasil apresentou nível de atividade aceitável durante o período. Verifica-se essa certa estabilidade ao observar os dados calculados para o índice $\mathrm{O}_{\mathrm{i}}$, dispostos no Gráfico 2 a seguir. Entre os anos de 2004 a 2008, o índice variou entre 1,7\% (2007) e 1,9\% (2008), diferença de $0,1 \%$ na abertura comercial.

Ademais, conforme destaca Moreira e Milhomenn (2010), após os anos de dificuldade do início da década, o Brasil experimentou um cenário de aceleração das exportações com o resto do mundo devido à combinação de múltiplos fatores. Entre eles destaca-se o contexto internacional favorável, fornecendo apoio ao crescimento global, mantendo estável a demanda e os preços dos produtos de exportações em níveis elevados em termos históricos.

Nesse sentido, segundo Cardoso (2008), na perspectiva de análise para um período positivo, no que se refere ao ano de 2004 , torna-se relevante destacar que a atividade econômica na América Latina aumentou bem acima dos anos anteriores, cerca de 5,9\%. Diferente do que acontecia, esse crescimento alcançou a maioria dos países do continente. "As baixas da taxa de juros e a elevada liquidez internacional também cumpriram uma importante função, ao 
A Liberalização Comercial Brasileira vista no âmbito do Mercosul a partir dos produtos...

proporcionar uma afluência de capital que favoreceu o ressurgimento do investimento e do consumo interno" (CARDOSO, 2008, p. 46). 
Gráfico 2. Índices de desenvolvimento do setor externo - Brasil MERCOSUL - 2000 a 2010

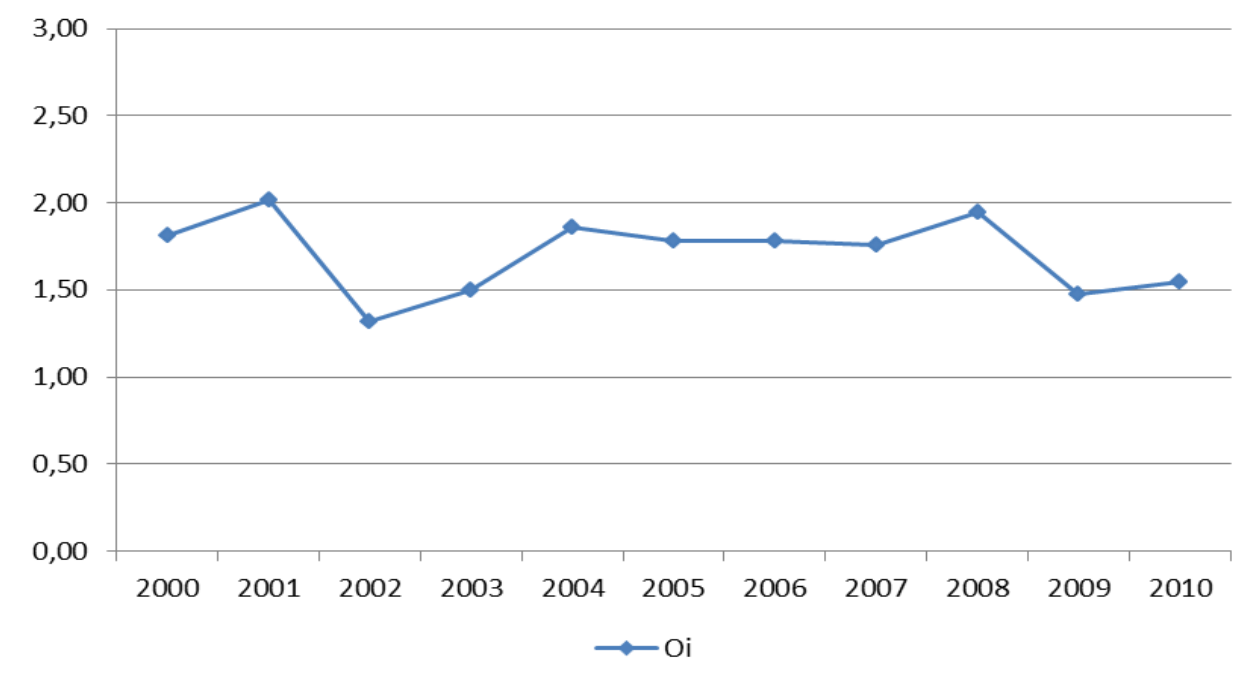

Fonte: Dados da pesquisa (2013).

O Gráfico 3 mostra o comportamento do SXi. Pode-se verificar a grande sensibilidade do SXi em relação ao cenário econômico internacional. O ano de maior liberalização comercial foi 2002, em contrapartida, o ano de menor liberalização ocorreu em 2009. Ficam evidentes os momentos de instabilidade mundial, caracterizados por significativas quedas no índice.

Como enfatizou Cardoso (2008), é relevante destacar a diferenciação de cada índice ao medir o desempenho do comércio internacional. Percebe-se a eficácia do $S X_{i}$ ao analisar o gráfico dos indicadores, este apresenta a economia sob uma ótica mais completa no contexto internacional, mostrando, de forma clara, o comportamento do setor externo da economia no decorrer dos acontecimentos mundiais. 


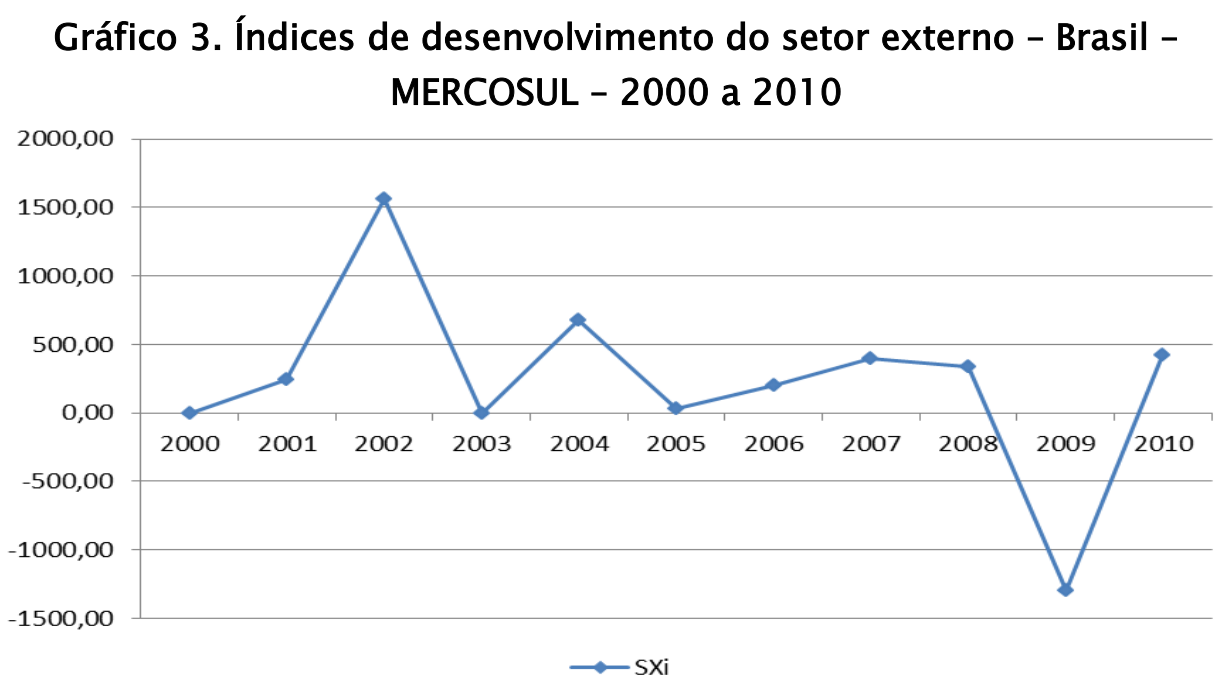

Fonte: Dados da pesquisa (2013).

No ano de 2008, foi deflagrada a pior crise do período em análise. A chamada crise do Subprime, iniciada no mercado imobiliário dos Estados Unidos, afetou a economia global. De acordo com Dias (2010), a economia brasileira não estava blindada contra a crise financeira internacional, devido à fragilidade financeira do setor produtivo. Outro fator importante foi a redução da margem de segurança das empresas devido ao otimismo generalizado do mercado, gerado pelos anos de estabilidade anteriores.

Com a crise do Subprime em 2008, o ano de 2009 apresentou um nível de baixa vulnerabilidade do $S X_{i}$, demonstrando que o setor externo não é o fator principal que afetou o crescimento do PIB, tendo em vista uma redução de $39 \%$ no IED em contraste com um crescimento de $5 \%$ no PIB. Cabe destacar que o volume de comércio de produtos manufaturados brasileiros apresentou decréscimo de $21 \%$. Fato este que acarretou redução na abertura comercial, como mostra o índice $\mathrm{O}_{i}$ que caiu de 1,94\%, em 2008, para 1,47\%, em 2009. O Gráfico 2 demonstra claramente essa queda.

A Tabela 4 mostra uma comparação entre o nível de vulnerabilidade do $S X_{i}$ e a performance do $E S_{i}$, especificando as transações comerciais com cada país-membro do MERCOSUL. Desconsiderando-se o volume de transações, verifica-se, com poucas exceções, certa semelhança nos resultados obtidos de forma isolada para cada um dos países-membros. 
Tabela 4. Comparação entre Performance $\left(E S_{i}\right)$, Vulnerabilidade $\left(S X_{i}\right)$ e Nível de Vulnerabilidade

\begin{tabular}{|c|c|c|c|c|c|c|}
\hline \multirow[b]{2}{*}{ Ano } & \multicolumn{3}{|c|}{ Argentina } & \multicolumn{3}{|c|}{ Paraguai } \\
\hline & $\begin{array}{c}\text { Performance } \\
\left(E S_{i}\right)\end{array}$ & $\begin{array}{l}\text { Vulnerab. } \\
\left(\mathrm{SX}_{\mathrm{i}}\right)\end{array}$ & $\begin{array}{l}\text { Nível de } \\
\text { Vulnerab. }\end{array}$ & $\begin{array}{c}\text { Performance } \\
\left(\mathrm{ES}_{\mathrm{i}}\right)\end{array}$ & $\begin{array}{l}\text { Vulnerab. } \\
\qquad\left(\mathrm{SX}_{\mathrm{i}}\right)\end{array}$ & $\begin{array}{l}\text { Nível de } \\
\text { Vulnerab. }\end{array}$ \\
\hline 2000 & - & - & - & - & - & - \\
\hline 2001 & Aceitável & Alta & 2.2 & Aceitável & Alta & 2.2 \\
\hline 2002 & Aceitável & Alta & 2.2 & Aceitável & Alta & 2.2 \\
\hline 2003 & Aceitável & Alta & 1.1 & Fraca & Baixa & 2.1 \\
\hline 2004 & Aceitável & Alta & 1.1 & Aceitável & Alta & 1.1 \\
\hline 2005 & Aceitável & Alta & 1.1 & Fraca & Baixa & 2.1 \\
\hline 2006 & Aceitável & Alta & 1.1 & Aceitável & Alta & 1.1 \\
\hline 2007 & Aceitável & Alta & 1.1 & Aceitável & Alta & 1.1 \\
\hline 2008 & Aceitável & Alta & 1.1 & Aceitável & Alta & 1.1 \\
\hline 2009 & Fraca & Baixa & 2.1 & Fraca & Baixa & 2.1 \\
\hline 2010 & Aceitável & Alta & 1.1 & Aceitável & Alta & 1.1 \\
\hline \multirow[b]{2}{*}{ Ano } & \multicolumn{3}{|c|}{ Uruguai } & \multicolumn{3}{|c|}{ Total } \\
\hline & $\begin{array}{c}\text { Performance } \\
\left(\mathrm{ES}_{\mathrm{i}}\right)\end{array}$ & $\begin{array}{c}\text { Vulnerab. } \\
\left(\mathrm{SX}_{\mathrm{i}}\right)\end{array}$ & $\begin{array}{l}\text { Nível de } \\
\text { Vulnerab. }\end{array}$ & $\begin{array}{c}\text { Performance } \\
\left(E S_{i}\right)\end{array}$ & $\begin{array}{c}\text { Vulnerab. } \\
\left(\mathrm{SX}_{\mathrm{i}}\right)\end{array}$ & $\begin{array}{l}\text { Nível de } \\
\text { Vulnerab. }\end{array}$ \\
\hline 2000 & - & - & - & - & - & - \\
\hline 2001 & Aceitável & Alta & 2.2 & Aceitável & Alta & 2.2 \\
\hline 2002 & Aceitável & Alta & 2.2 & Aceitável & Alta & 2.2 \\
\hline 2003 & Fraca & Baixa & 2.1 & Fraca & Baixa & 3.1 \\
\hline 2004 & Aceitável & Alta & 1.1 & Aceitável & Alta & 1.1 \\
\hline 2005 & Aceitável & Alta & 1.1 & Aceitável & Alta & 1.1 \\
\hline 2006 & Aceitável & Alta & 1.1 & Aceitável & Alta & 1.1 \\
\hline 2007 & Aceitável & Alta & 1.1 & Aceitável & Alta & 1.1 \\
\hline 2008 & Aceitável & Alta & 1.1 & Aceitável & Alta & 1.1 \\
\hline 2009 & Fraca & Baixa & 2.1 & Fraca & Baixa & 2.1 \\
\hline 2010 & Aceitável & Alta & 1.1 & Aceitável & Alta & 1.1 \\
\hline
\end{tabular}

Fonte: Dados da pesquisa (2013).

O nível de vulnerabilidade normal, ou seja, que demonstra que o país não está muito susceptível quanto aos acontecimentos externos, resultado de um IED e um Volume de Comércio crescendo mais rapidamente que o PIB, não ocorreu em nenhum dos anos em análise. Pelos cálculos realizados, fica evidente que em todos os anos da última década o setor externo, de produtos manufaturados exportados e importados pelo Brasil a países-membros do MERCOSUL, influenciaram as tendências do PIB.

O MERCOSUL continua se expandindo e seus indicadores macroeconômicos demonstram a solidez e a maturidade que o bloco 
continua atingindo, sobretudo por meio das empresas que usam inovações tecnológicas, melhorando a qualidade do produto e, consequentemente, o bem-estar da região. Medidas estão sendo tomadas para diminuir as assimetrias ainda existentes no âmbito do bloco, como a criação do FOCEM4 (MOREIRA e MILHOMENN, 2010).

O MERCOSUL apresentou resultados consideráveis como bloco de integração desde a sua instituição, visto que o mesmo atingiu seu objetivo quanto à criação de comércio, acelerando o desenvolvimento socioeconômico dos países-membros e, por consequência, ganhando cada vez mais espaço no cenário econômico internacional.

Destaca-se que, na prática, a integração entre Brasil, Argentina, Uruguai e Paraguai avançou rapidamente nas relações comerciais no primeiro período do bloco (LAMPREIA, 1999, apud CARDOSO, 2008, p. 47) ${ }^{5}$. Nos últimos tempos, o aprofundamento ficou mais difícil. A agenda negociada em 1995 não foi totalmente cumprida até o momento. A integração do setor de serviços também não progride conforme o esperado pelos países. Não há mecanismos e, consequentemente, agilidade na solução de controvérsias. O grande clamor é pela organização de um sistema arbitral, realmente neutro e detentor de notoriedade capaz de solucionar entraves, evitando que os avanços dependam apenas do diálogo político, como tem sido até o presente momento, diga-se, pouco eficaz.

\section{CONSIDERAÇÕES FINAIS}

O objetivo deste trabalho foi analisar o desempenho da economia brasileira em relação ao comércio de produtos manufaturados, destinados aos demais países-membros do MERCOSUL entre 2000 e 2010. Para tanto, traçou-se um panorama relatando as dificuldades bem como as relações comerciais entre os membros do bloco. Com fins de atingir os objetivos elencados neste trabalho, efetuou-se o cálculo de índices de abertura comercial e de desenvolvimento do setor externo de produtos manufaturados exportados pelo Brasil.

\footnotetext{
4 Fundo para a Convergência Estrutural e Fortalecimento Institucional do MERCOSUL.

5 LAMPREIA, L. F. Que futuro para o Mercosul? Classe inaugural do Ministro das Relações Exteriores na Cátedra Mercosul do Instituto de Estudos Políticos de Paris. 1999. Disponível em: <www.mre.gov.br>. Acesso em: 12 ago. 2008.
} 
Os dados da pesquisa demonstraram relativa estabilidade quanto à abertura comercial em relação aos produtos manufaturados, conforme os resultados obtidos pelo índice $\mathrm{O}_{\mathrm{i}}$. Como demonstrado por meio do SX, na maioria dos anos analisados, o Brasil apresentou um nível de Alta Vulnerabilidade, demonstrando que a variação do volume de comércio, representado pela exportação e importação de produtos manufaturados, a variação do PIB e do IED se moveram na mesma direção. Quanto ao desempenho do $E S_{i}$, com exceção dos anos de 2003 e 2009, mantevese em níveis aceitáveis.

Dentre os países integrantes do MERCOSUL, a Argentina destacou-se como maior parceiro comercial brasileiro, importando, em média, mais de $80 \%$ do total de produtos manufaturados exportados para o bloco durante a última década. Em seguida, o Paraguai importou do Brasil uma média de $11 \%$ e, por fim, o Uruguai, que deteve cerca de $8 \%$ do total. Essas informações seguem alinhadas aos resultados do Índice de Abertura comercial $\mathrm{O}_{\mathrm{i}}$, demonstrando que o Brasil é mais aberto em relação à Argentina, tendo em vista um $\mathrm{O}_{i}$ com média de 1,4\% no período analisado, seguidos por $0,1 \%$ de média nos outros dois países.

Ficou evidente entre os resultados dos índices a eficácia do $S X_{i}$ ao analisar o cenário econômico em que o Brasil está inserido. Esse índice apresentou a economia brasileira sob uma ótica mais completa no contexto internacional, mostrando de forma clara o comportamento do setor externo no decorrer dos acontecimentos mundiais.

Pode-se dizer que a formação do MERCOSUL trouxe claros benefícios em relação ao mercado de produtos manufaturados brasileiros. Verificou-se que, entre os anos de 2000 e 2010, as exportações totais desses produtos cresceram mais de 190\%. Esse incremento comercial proporcionou o surgimento de instituições, especialização e melhoria de mão de obra em empresas exportadoras, melhorias na infraestrutura de telecomunicações, diversificação e melhoria dos produtos através de inovações tecnológicas, contribuindo para o desenvolvimento do país.

Conforme citado por diversos autores, como Baumann (2011), Cardoso (2008) e Grimaldi et al (2012), a integração não se verificou apenas em termos de comércio, e sim no aumento dos investimentos, causando maior interdependência entre os países-membros. Somente o 
Brasil obteve um incremento nos IEDs de mais de $50 \%$ na década passada. Esse incremento resultou no destaque brasileiro, tendo em vista que a grande maioria dos produtos exportados pelo Brasil, em média mais de $90 \%$ do total, tem grande valor agregado. Evidenciou-se, portanto, o importante papel brasileiro dentro do bloco.

\section{REFERÊNCIAS}

ALMEIDA, Odília. Mercosul completa 20 anos como união aduaneira imperfeita. Rio de Janeiro, 31 mar., 2011. Disponível em: <http://puc-riodigital.com.pucrio. $\mathrm{br} / \mathrm{cgi} /$ cgilua.exe/sys $/$ start.htm?infoid=8937\&sid=42>. Acesso em: 29 jan. 2014.

ALMEIDA, P. R. MERCOSUL e ALCA na perspectiva do Brasil. IN O Brasil e a Alca. Instituto de Pesquisa de Relações Internacionais, Rio de Janeiro, 2002.

BALASSA, B. Teoria da integração econômica. Lisboa: Livraria Clássica Editora, 1964.

BAUMANN, R. MERCOSUL: origens, logros, desencontros e perspectivas. In: América Latina. Crescimento no comércio mundial e exclusão social. Porto Alegre: Dacasa, 2001 a.

MERCOSUL: avanços e desafios da integração. Brasília: IPEA/CEPAL, $2001 \mathrm{~b}$

Economia internacional: teoria e experiência brasileira. Rio de Janeiro: Elsevier, 2004.

O MERCOSUL aos vinte anos: uma avaliação econômica. Instituto de Pesquisa Econômica Aplicada (IPEA, TD 1627), Brasília, 2011.

BECKER, J. Integración y regulación: La Unión Europea y el Mercosur comparados. In. GUDYNAS, Eduardo (org.) Sustentabilidad y Regionalismo em el Cono Sur. Montevidéu: Coscoroba, 2002.

BÊRNI, D. A. A Marcha do MERCOSUl e a Marca da Globalização. Indicadores Econômicos FEE, Porto Alegre: v.29, n.3, 2001.

BRUM, A. L. A economia internacional na entrada do século XXI: transformações irreversíveis. $2^{\text {a }}$ ed. Ijuí: Unijui, 2002.

Redes (St. Cruz Sul, Online), v. 20, n³ 3 - Suplemento, p. 401 - 425, set./dez. 2015430 
BOUZAS, R. MERCOSUL, dez anos depois: processo de aprendizado ou déjà-vu? Revista brasileira de comércio exterior, Rio de Janeiro, 2001.

CARDOSO, R. D. Índices de desenvolvimento do setor externo de uma economia: uma análise para o MERCOSUL. 2008. Monografia (Bacharelado em Ciências Econômicas) - Universidade Estadual do Oeste do Paraná, Toledo, 2008.

CAVALCANTE, J. e MERCENIER, J. Uma avaliação dos ganhos dinâmicos do MERCOSUL usando Equilíbrio Geral. Fórum BNB de Desenvolvimento-IX Encontro Regional Em Economia - Uma Política para o Nordeste, 2004.

CEPAL, Los processos de integración de los países de América Latina y el caribe 2000-2001: avances, retrocesos y temas pendientes. Santiago de Chile, 2002.

DAVID, M. B. A; NONNENBERG M. J. B. MERCOSUL: Integração regional e o comércio de produtos agrícolas. Rio de Janeiro: Instituto de Pesquisa Econômica Aplicada, 1997. (IPEA - Texto para Discussão: 494).

DIAS, E. L. C. Política Fiscal e a Crise Econômica Internacional. Finanças Públicas - $3^{\circ}$ Lugar - XV Prêmio Tesouro Nacional, 2010.

EDWARDS, S. Openness, trade liberalization, and growth in developing countries. Journal of Economic Literature, v. 31, 1998.

Jornal O Estado de São Paulo. Fracassa Tentativa de acordo no MERCOSUL. Jornal O Estado de São Paulo, 01/12/2008.

GIAMBIAGI, F.; BARENBOIM, I. MERCOSUL: por uma nova estratégia brasileira. Rio de Janeiro: Instituto de Pesquisa Econômica Aplicada, 2005 (Texto para Discussão $N^{\circ} 1131$ ).

GIAMBIAGI, F. MARKWALD, M. M. A estratégia de inserção do Brasil na economia mundial: MERCOSUL ou lonely runner? Rio de Janeiro: Ensaios BNDES, 2002. (Texto para discussão, n. 14).

GRIMALDI, D.; CARNEIRO, F.; OLIVEIRA, L. F. Padrões de especialização comercial no MERCOSUL. Brasília: Instituto de Pesquisa Econômica Aplicada, 2012. (Texto para Discussão, 1692). 
JOHNSON, $\mathrm{H}$. The economic theory of protectionism, tariff bargaining and the formation of customs unions. Journal of Political Economy, n. 73, 1965.

KUME, Honório. MERCOSUL 1995: uma avaliação preliminar. A economia brasileira em perspectiva. Rio de Janeiro: Instituto de Pesquisa Econômica Aplicada, 1996.

MACHADO, J. B. MERCOSUL: processo de integração. Origem, evolução e crise. São Paulo: Aduaneiras, 2000.

MOREIRA, S. A.; MILHOMEM E. É. L. Evolução recente do comércio exterior brasileiro com os países do MERCOSUL. Brasília: Instituto de Pesquisa Econômica Aplicada, 2010. (IPEA - Texto para discussão: 1466).

NONNENBERG M. J. B. e MESENTIER A. A criação do Mercosul contribuiu para aumentar a intensidade tecnológica das exportações da região? Brasília: Instituto de Pesquisa Econômica Aplicada, 2011 (IPEA - Texto para Discussão: 1644).

RUIZ, M. A. The External Sector Development Index $\left(S X_{i}\right)$. Social Science Research Network. 2004. Disponível em:

$<$ http://papers.ssrn.com/sol3/papers.cfm?abstract_id=67304 1 >. Acesso em: 05 mar. 2013.

SICA, D. Mudança Estrutural, Investimento Externo e Intercâmbio Comercial nas duas Maiores Economia do MERCOSUL. Revista Brasileira de Comércio Exterior, Rio de Janeiro, RJ, FUNCEX, v. 18, n. 81, 2004.

VASCONCELOS, C. R. F. O Comércio Brasil - Mercosul na década de 90: Uma análise pelas óticas da intensidade fatorial, comércio intra-indústria e criação e desvio de comércio. Recife: Universidade Federal de Pernambuco (Tese de Doutorado), 2000.

VINER, J. The customs union issue - carnegie endowment for international peace. New York, 1950.

VIZENTINI, P. G. F. Dez Anos do MERCOSUL: a crise da integração e o desafio da ALCA. Indicadores Econômicos FEE, Porto Alegre : v.29, n.1, 2001.

O Brasil, o MERCOSUL e a Integração da América do Sul. Revista de estudos e pesquisas sobre as Américas, Brasília, 2007. 
Submetido em 28/04/2014

Aprovado em $01 / 12 / 2015$

\section{Sobre os autores}

\section{Fagner Mendonça Avelar}

Economista e Mestrando em Economia pela Universidade Estadual do Oeste do Paraná - UNIOESTE/ Campus de Toledo.

Endereço: Rua da faculdade, 645, Prédio do CCSA. 85903-000 - Toledo - PR - Brasil.

E-mail: fmavelar@hotmail.com.

\section{Cristiano Stamm}

Doutor em Planejamento Urbano e Regional pela Universidade Federal do Rio Grande do Sul. Professor Adjunto do Colegiado do Curso de Economia e do Mestrado em Economia da UNIOESTE/Campus de Toledo. Pesquisador do Grupo de Pesquisa em Agronegócio e Desenvolvimento Regional (GEPEC). Editor da Revista Informe GEPEC UNIOESTE/Campus de Toledo.

Endereço: Rua da faculdade, 645, Prédio do CCSA, sala 14. 85903-000 - Toledo - PR Brasil.

E-mail: stamm_br@yahoo.com.br

\section{Carlos Gonçalves}

Doutorando em Desenvolvimento Econômico pela FEA/USP. Mestre em Desenvolvimento Regional e Agronegócio pela Universidade Estadual do Oeste do Paraná - UNIOESTE/Campus de Toledo. Economista pela Universidade Estadual de Maringá - UEM. Professor Assistente do Colegiado do Curso de Economia da UNIOESTE/Campus de Toledo. Pesquisador do Grupo de Pesquisa em Agronegócio e Desenvolvimento Regional (GEPEC). Universidade Estadual do Oeste do Paraná UNIOESTE/Campus de Toledo.

Endereço: Rua da faculdade, 645, Prédio do CCSA, sala 15.85903-000 - Toledo - PR Brasil.

E-mail: carlosalbertojr@hotmail.com 